\title{
International Standards to document remaining Autonomic Function after Spinal Cord Injury (ISAFSCI), First Edition 2012
}

\author{
Contributors: Andrei Krassioukov, $M D, P h D$, Chair, Fin Biering-Sorensen, $M D, D M S c$, \\ William Donovan, MD, Michael Kennelly, MD, Steven Kirshblum, MD, Klaus Krogh, MD, \\ $P h D, D M S c$, Marca Sipski Alexander, MD, Lawrence Vogel, MD, and Jill Wecht, EdD
}

\section{Preface to the Journal Edition}

During the last decade an international community of clinicians and scientists in the area of spinal cord injury (SCI) medicine became aware of the need to improve evaluation of autonomic function in individuals with SCI to optimize clinical management and determine efficacy of therapeutic interventions. This prompted an international collaboration between the American Spinal Injury Association (ASIA) and the International Spinal Cord Society (ISCoS) to develop the International Standards documenting the remaining autonomic functions following SCI.

The autonomic nervous system (ANS) plays a key role in regulation of many physiologic processes.Impact of SCI on autonomic control cannot be overstated because supraspinal control of many bodily systems and organs is partially or completely lost following an injury to the spinal cord. Although autonomic dysfunctions are well recognized clinically, the mechanisms of these dysfunctions are still poorly understood and present significant challenges during clinical management of the secondary complication of SCI.

Understanding the role of autonomic dysfunction in persons with SCI is crucial to improving health and longevity in these individuals because ANS dysfunction may be the underpinning of many secondary complications post-SCI. Furthermore,

Recommended citation: American Spinal Injury Association: International Standards to document remaining Autonomic Function after Spinal Cord Injury, 2012; Atlanta, GA. it is known that restoration of autonomic function is among the highest health priorities for individuals with SCI. However, research initiatives aimed at gaining insight into the direct impact of ANS dysfunction on health outcomes in persons with SCI are currently lacking.

This publication presents a revised edition of the International Standards on documentation of remaining Autonomic Function after SCI (ISAFSCI) and will be of interest to anyone involved in clinical management of individuals with SCI. The objectives of this ISAFSCI initiative are to describe the impact of SCI on ANS function and to provide clinicians with an assessment tool which is recommended for evaluation of autonomic dysfunctions following SCI. This newly designed form is recommended to be completed during the evaluation of individuals with SCI as an adjunct to the International Standards for Neurological Classification of Spinal Cord Injury (ISNCSCI) to document the neurological level and

$\overline{\text { Copyright } \odot} 2012$ American Spinal Injury Association (ASIA). This booklet is intended for the express use of training professionals in the use of the International Standards to document remaining Autonomic Function after Spinal Cord Injury. No part of this publication may be modified, reproduced, stored in a retrieval system, or transmitted in any form or by any means, electronic, photocopying, recording or otherwise, without prior written permission of ASIA. All rights reserved.

The only portion is this booklet to which this prohibition of modification, reproduction, storage in a retrieval system or transmission in any form does not apply is the "Autonomic Standards Assessment Form." Notice is found at the bottom of that page which attests to the permission granted by ASIA for duplication, but alteration of this form in any manner is prohibited without permission from ASIA.

Top Spinal Cord Inj Rehabil 2012;18(3):282-296 www.thomasland.com

doi: $10.1310 /$ sci1803-282 
completeness of the spinal lesion in individuals with SCI including the ASIA Impairment Scale (AIS). A compilation of what is known about cardiovascular, respiratory, bladder, bowel, temperature, and sexual dysfunction after SCI, as it relates to the changes within the ANS control of these functions, can be found in the Autonomic Standard Assessment Form.

Additionally, a web-based training course has been developed to assist clinicians with understanding autonomic dysfunctions following SCI: the Autonomic Standards form (ASTeP). We encourage the reader to access ASTeP for additional information (www.ASIAlearningcenter.com).

Members of the Autonomic Standards Committee expect that publication of the ISAFSCI will facilitate the practical use and testing of the Autonomic Standards which will promote improved clinical care, and subsequent health and longevity for the SCI community. Considering the complexity of ANS function and the paucity of standardized tests for evaluation in individuals with SCI we expect this document to be revised and refined over time and we welcome comments and constructive criticism that will facilitate further refinement and improvement of this evaluation process for autonomic function post-SCI. This is just the beginning of an exciting future in the exploration of autonomic function, and establishment a validated autonomic classification tool for individuals with SCI.

-Andrei Krassioukov, MD, PhD

Chair

ASIA/ISCoS Autonomic Standards Committee May 2012

\section{Preface to the First Edition}

During the last decade an international community of clinicians and scientists in the area of spinal cord injury (SCI) medicine became aware of the need for improved evaluation of autonomic function in individuals with SCI for improved clinical management and to determine efficacy of therapeutic interventions. This prompted an international collaboration between the American Spinal Injury Association (ASIA) and the International Spinal Cord Society
(ISCoS) to develop the International Standards documenting the remaining autonomic functions following SCI.

This is the first edition of the booklet describing the International Standards to document remaining Autonomic Function after Spinal Cord Injury (ISAFSCI). This booklet should be used as an adjunct with the International Standards for Neurological Classification of Spinal Cord Injury (ISNCSCI) that documents the neurological examination of individuals with SCI including the ASIA Impairment Scale (AIS). The Autonomic Standards Assessment Form is recommended to be completed during the evaluation of individuals with SCI, but is not a part of the ISNCSCI. Additionally, a web-based training course has been developed both to assist clinicians with understanding autonomic dysfunctions following SCI and with completion of the Autonomic Standards Assessment Form. We encourage the reader to access Autonomic Standards Training E Program (ASTeP) for additional information (www.ASIAlearningcenter.com). ${ }^{1}$

The Autonomic Standards Committee recognizes that this is only a first attempt in our efforts to use previous experience with neurological classification of SCI to bring knowledge to a more complex system such as the autonomic nervous system. Furthermore, the committee acknowledges that the complexity and organization of the autonomic nervous system and its involvement in the control of almost every organ system in the body makes selecting appropriate autonomic function tests for individuals with SCI difficult. Finally, we realize that experience with these tests in the clinical assessment of individuals with SCI is very limited, given that uniform operational definitions of dysfunction are lacking.

Members of the Autonomic Standards Committee expect this booklet to be revised and we welcome comments and constructive criticism that will facilitate further refinements and improvements of the evaluation of the autonomic functions of individuals with SCI.

-Andrei Krassioukov, MD, PhD Chair

ASIA/ISCoS Autonomic Standards Committee January 2012 


\section{Introduction}

Currently, the ISNCSCI ${ }^{2}$ are used to document impairments of only motor and sensory function after SCI. These standards are now in the seventh edition. However, SCI, especially cervical lesion levels, may be life threatening because of the imbalance in the autonomic nervous system (ANS) function. Furthermore, this imbalance might be a risk factor for progressive deterioration of neurological function following SCI.

Despite success with the ISNCSCI, assessment of remaining autonomic function after SCI is lacking. The joint Autonomic Standards Committee of ASIA and ISCoS supported a working group to develop a framework for the assessment and documentation of specific autonomic function in individuals following SCI. In 2009, this group published the first version of the international standards to assess remaining autonomic function. ${ }^{3}$ It was recommended that this assessment should be part of the clinical evaluation of individuals with SCI.

Since the original publication of the ISAFSCI, practical clinical experience in using the tool has been gained prompting modifications of the standards.

In this booklet we omitted the urodynamic component of the ISAFSCI. Although extremely valuable, the methodology and interpretation of urodynamics is too complex to include in these standards. This group strongly recommends that patients have urodynamic studies as a part of their SCI autonomic assessment and endorses the use of the International Spinal Cord Injury Urodynamic Basic Data Set (see Appendix II). ${ }^{4}$

It is anticipated that ISAFSCI and this booklet will be revised in the future. Any comments or recommendations regarding revisions are greatly appreciated and should be forwarded to ASIA_ Office@shepherd.org.

\section{General anatomic and physiologic considerations}

Blood vessels, heart, respiratory tract, sweat glands, bowel, urinary bladder and sexual functions are under nervous system control: autonomic (involuntary), somatic (voluntary) or both. During micturition and defecation, there are coordinated actions of the striated muscles of the external urethral and anal sphincters (both under voluntary cortical control by the somatic nervous system) and smooth muscles of the bladder and the bowel (both under involuntary control by the ANS). Cortical control also plays an important role in sexual arousal, resulting in psychogenic erection and vaginal lubrication. However, reflex erection or lubrication, ejaculation, and orgasm can be achieved with peripheral stimulation, even when cortical influences are disrupted. On the other hand, many aspects of cardiovascular and sudomotor control are primarily dependent on the interplay of sympathetic and parasympathetic nervous system activity. SCI disrupts the descending spinal voluntary motor and involuntary autonomic pathways, resulting in dysfunctions of the cardiovascular and broncho-pulmonary systems, sudomotor, urinary bladder, bowel and sexual organs. The level and the severity of injury to these pathways results in a variety of autonomic dysfunctions depending on the altered supraspinal control of the sympathetic and parasympathetic nervous systems.

\section{Autonomic nervous system: anatomy and function}

The ANS is commonly subdivided into two major parts: the sympathetic and parasympathetic components. Most of the visceral organs are innervated by both components of the ANS. The sympathetic and parasympathetic systems are integrated functionally with each other within the central nervous system and provide balanced regulation of innervated organs. Certain cortical structures, and the hypothalamus, contribute to regulation of the autonomic circuits within the brainstem and spinal cord.

Both divisions of the ANS have two neuronal populations interposed between the central nervous system and target organs. The first neuron is called the preganglionic neuron, with the cell body within the gray matter of the brain 
Table 1 Organization of innervation of major organs

\begin{tabular}{|c|c|c|c|}
\hline Organ & $\begin{array}{l}\text { Sympathenic } \\
\text { nervous system } \\
(71-(2)\end{array}$ & $\begin{array}{l}\text { Povosympothetic nervous system } \\
\text { vogus nerve (ION) and (52-4) }\end{array}$ & Somatiofmotor \\
\hline Heart & T1-TS & Vagus serve (ONX) & None \\
\hline \multicolumn{4}{|l|}{ Blilood vessets } \\
\hline Upper boty & I1-IS & Slood vessels in certain organc & None \\
\hline lower body & TS-12 & $\begin{array}{l}\text { salivary glands, gastrointestinal } \\
\text { glands (ION X), and genital } \\
\text { erectile tissoer (S2-S4) }\end{array}$ & \\
\hline Brincho-pulmanary grtem & Tl-TS & Voyus serve (ONX) & $0-8$ \\
\hline Sweat glonds & $\pi 1-12$ & Nooe & None \\
\hline Face & $\mathrm{T1}-\mathrm{I} 4$ & Noee & None \\
\hline Reminder of the body & $\pi 1+2$ & Nose & None \\
\hline \multicolumn{4}{|l|}{ Lower wrinory troxt } \\
\hline Detrusar & $110-12$ & $\$ 2.54$ & \\
\hline Bladder neck/internal urethral & & & \\
\hline sphincter & $\pi 10-12$ & Noese & \\
\hline Extemal urethal sphincter & $\mathrm{T10}-12$ & None & $53-55$ \\
\hline \multicolumn{4}{|l|}{ Gostro-interstinal troct } \\
\hline From esophagos to splenic flexure & $\pi 1-12$ & Vagus nerve (ONX) & \\
\hline $\begin{array}{l}\text { From splenic flecure to rectum/ } \\
\text { internal anal sphincter }\end{array}$ & T1-12 & $52-54$ & \\
\hline Extemal anal sphincter & $110-42$ & $\$ 2.54$ & 53.55 \\
\hline \multicolumn{4}{|l|}{ Genitalio and reproductive orgars } \\
\hline Vaging & $110-12$ & $\$ 2-54$ & $\$ 1-53$ \\
\hline Female reproductive organs & $\pi 10-42$ & 52.54, Vagus nerve (ONX) & $\$ 1.53$ \\
\hline Penis & $110-12$ & $\$ 2-54$ & $\$ 1-53$ \\
\hline Male repenductive organs & $\pi 10-42$ & $\$ 2.54$ & $\$ 1.53$ \\
\hline
\end{tabular}

Abbreviztions: $\mathrm{C}$, cervical; $\mathrm{CN}$, canial nerve; L, lumbar; S, sacral; t, theracic.

or spinal cord. Axons of these neurons, called preganglionic fibers, travel within the ventral roots of the spinal cord or cranial nerves. These fibers synapse on the second group of neurons, called postganglionic. This group of neurons is located within the autonomic ganglia in the peripheral nervous system. The axons of these neurons, called postganglionic fibers, innervate the target organs. Sympathetic preganglionic neurons reside in the spinal gray matter in the thoracic (T1-T12) and upper lumbar segments (L1-L2) of the spinal cord. The majority of sympathetic preganglionic neurons are localized within the lateral horns or intermediolateral nucleus of the spinal cord. Axons of the sympathetic preganglionic neurons exit through the ventral roots and synapse on postganglionic sympathetic neurons located in the spinal paravertebral ganglia (sympathetic chain ganglia) and prevertebral ganglia (the celiac, superior and inferior mesenteric ganglia). The postganglionic neurons then send their axons through the peripheral nerves to innervate the target organs, including the heart, blood vessels, respiratory tract, sweat glands, sexual organs, bowel, and urinary bladder (Table 1). Parasympathetic preganglionic neurons are located within the nuclei of four cranial nerves (CN III, VII, IX, X) in the brainstem and within the sacral spinal segments (S2-S4).

Parasympathetic control of the cardiovascular system and the upper portion of the gastrointestinal tract is through the vagus nerve $(\mathrm{CN} \mathrm{X})$, which exits from the brain through the base of the skull and reaches the sino-atrial (SA) node of the heart and the nerve cells within the enteric nervous system of the bowel. There is no parasympathetic innervation of the peripheral vasculature except in the pelvic organs. Parasympathetic innervation of the urinary bladder, reproductive organs and lower portion of the gut is provided by the sacral portion of the spinal cord (S2-S4) (Table 1).

\section{Neural control of the cardiovascular system}

Vessels in the upper portion of the body and the heart receive sympathetic innervation from the T1T5 spinal sympathetic neurons, whereas the major vasculature beds in the gut and lower extremities 


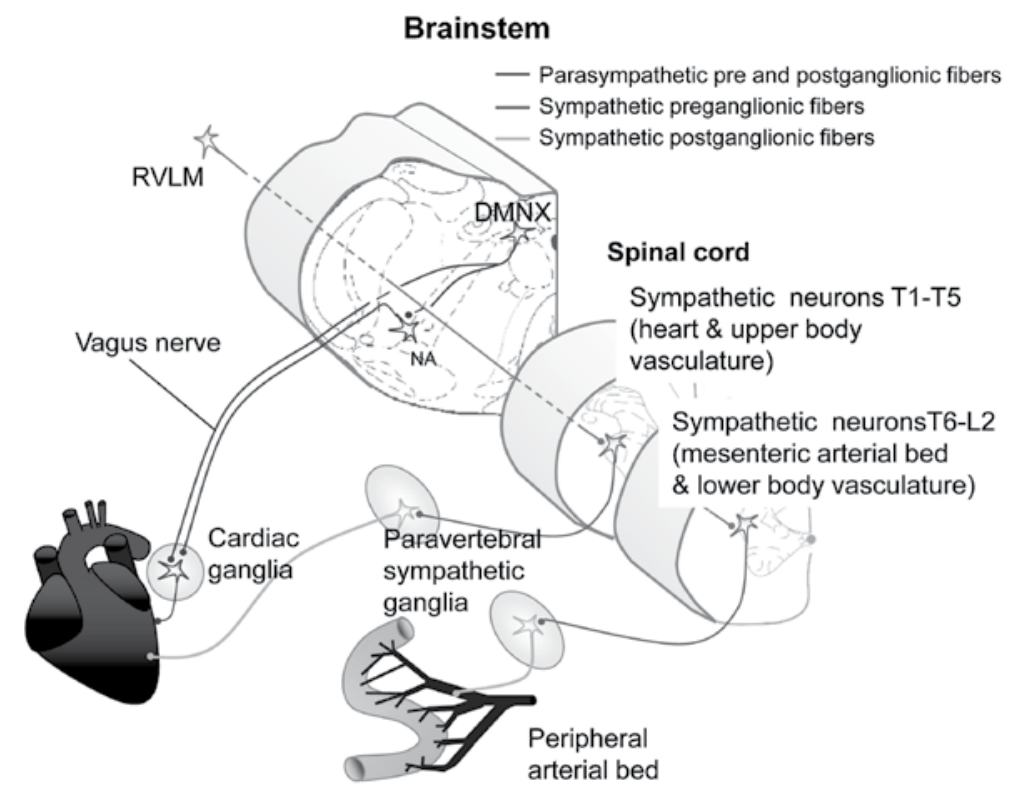

Figure 1. Autonomic efferent innervation of the cardiovascular system. The major organs of the cardiovascular system are the heart and the blood vessels. The heart receives both parasympathetic and sympathetic innervation. Parasympathetic efferent fibers travel to the heart via the vagus nerve $(C N X)$, which exits the central nervous system at the level of the medulla and includes the dorsal vagal motor nerve (DMNX) and nucleus and nucleus ambigus (NA). The vagal nerve innervates the atria, nodes, and Purkinje fibers via local cardiac ganglia. Vagal stimulation decreases heart rate, contractility, and conduction velocity. The primary neurotransmitter released by pre-ganglionic and postganglionic parasympathetic fibers $(\mathrm{CN} \mathrm{X})$ is acetylcholine.

All tissues of the heart receive sympathetic innervation from the upper thoracic (T1-T5) cord and sympathetic stimulation increases heart rate, contractility and conduction velocity. The peripheral vasculature receives tonic sympathetic control, which is provided by the medullar cardiovascular center known as rostroventrolateral medulla (RVLM). The vessels supplying the splanchnic region - the liver, spleen, and intestines - are most important in cardiovascular control. The splanchnic bed is densely-innervated, highly compliant, and contains approximately one-fourth of the total blood volume in humans at rest. As such, it is the primary capacitance bed in the body. Sympathetic oufflow to the splanchnic bed exits the thoracolumbar cord (T5-L2) and provides tonic vasoconstriction via alpha adrenoreceptors. The preganglionic sympathetic neurotransmitter is acetylcholine and the postganglionic sympathetic neurotransmitter is norepinephrine, which is integral to the maintenance of tonic vasoconstriction.

Baroreceptor (afferent) control of cardiovascular system is not shown. (Modified from Inskip et al. 2009 Spinal Cord with permission ${ }^{5}$

are under the control of the more caudal T5L2 spinal sympathetic neurons. In addition to sympathetic fibers, the SA node is also innervated by postganglionic parasympathetic fibers from the vagus nerve $(\mathrm{CN} \mathrm{X})$, providing tonic inhibition of the SA node which tends to lower the HR. Dual innervation of the heart and the segmental differences in sympathetic innervation to a variety of vascular beds are particularly important for the understanding of basal blood pressure and $\mathrm{HR}$, as well as cardiovascular responses following cervical, mid-thoracic, or lower thoracic SCI. ${ }^{6}$

\section{Neural control of the broncho-pulmonary system}

Similar to other organ systems, impairment in respiratory function is directly related to level and completeness of the lesion following SCI. ${ }^{7}$ In individuals with an intact central nervous system, respiration occurs through coordinated activity of the somatic nervous system (control of inspiratory and expiratory muscles) and the autonomic nervous system (bronchial tone and secretions). The diaphragm is the major muscle of inspiration and is innervated by the phrenic nerve (C3-C5). 


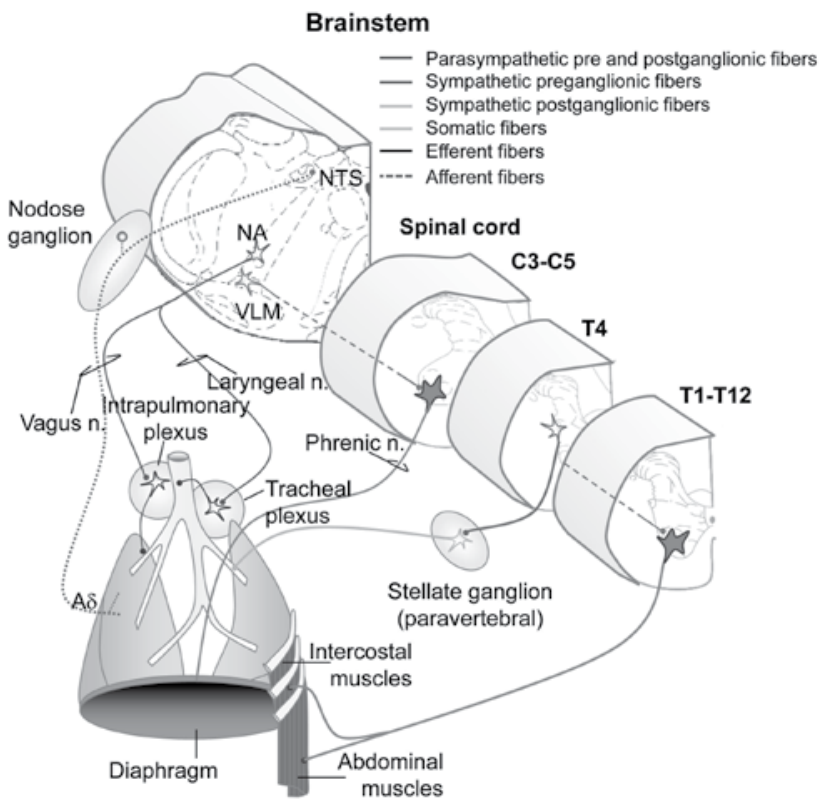

Figure 2. Innervation of the respiratory system. The diaphragm is the major inspiratory muscle and is innervated by phrenic motor neurons that lie in the cervical spinal cord (C3-C5). Innervation of respiratory intercostal and abdominal muscles exit the thoracolumbar spinal cord, from T1-T1 1 and T7-L2, respectively. Activity of these muscles (as well as that of accessory muscles) is modulated by autonomic pre-motor neurons in the ventrolateral medulla (VLM), which project to motor neurons in the spinal cord.

The airways receive both parasympathetic and sympathetic input. The parasympathetic nervous system provides the innervation to the smooth muscle of the airways, and is thus most important in controlling airway diameter. Preganglionic parasympathetic neurons originate in the nucleus ambiguous (NA), and innervate the trachea and the bronchi via the laryngeal and vagus nerves (respectively). Parasympathetic innervation is conveyed via acetylcholine and its action is excitatory resulting in broncho constriction. Sympathetic innervation of smooth muscle is comparatively scant. Preganglionic sympathetic axons exit at T4 and travel to paravertebral ganglia, and post-ganglionic adrenergic fibers elicit bronchodilation, acting through $\beta$-adrenergic receptors. The airways also have extensive afferent innervation. The most important afferents regulating respiration are vagal mechanoreceptors, with cell bodies in the nodose ganglia and central axons projecting to the nucleus of the solitary tract (NTS). (Modified from Inskip et al. 2009 Spinal Cord with permission ${ }^{5}$ )

Persons with cervical SCI below C4 usually maintain the ability to breathe spontaneously, but manifest greater reduction in vital capacity and more severe restrictive impairment than persons with thoracolumbar injury. Expiratory muscle function, especially the ability to generate forceful cough for airway clearance, may be severely impaired in persons with cervical SCI and to a lesser extent in those with lower levels of injury because of paralysis of abdominal muscles and the lateral internal intercostals (T1-T12).

Autonomic control of the bronchopulmonary system is principally governed by the parasympathetic nervous system. Sympathetic neurotransmission to the broncho-pulmonary system arising from the sympathetic chain at the T1-T6 level has historically been felt to have little functional significance in human airways. However, studies in persons with cervical SCI in whom sympathetic innervations to the broncho-pulmonary system are interrupted, reveal reduction in baseline airway caliber and exaggerated bronchial responsiveness (bronchoconstriction).

\section{Neural control of sweat glands}

Similar to blood vessels, the sweat glands are predominantly under sympathetic control. Sweat glands in the upper portion of the body receive 


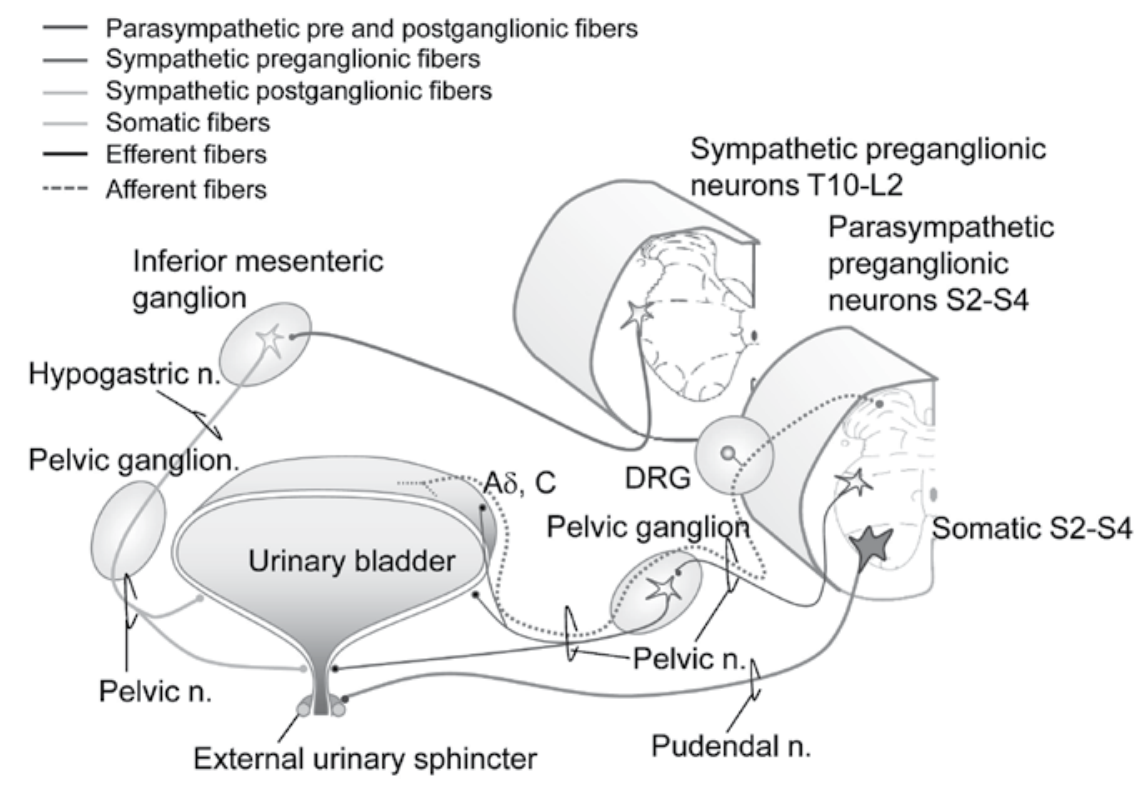

Figure 3. Innervation of the lower urinary tract. The lower urinary tract (LUT) is comprised of the bladder, the urethral sphincter, and the urethra. The LUT receives the bulk of its innervation from three nerves. The hypogastric nerve carries sympathetic innervation to the bladder and is responsible for urinary storage that is mediated by $\alpha$-adrenergic receptors expressed in the trigone, bladder neck, and urethra (excitatory), and by $\beta$-adrenergic receptors expressed in the bladder dome (inhibitory). The pelvic nerve contains parasympathetic input originating in the sacral cord (S2-S4) and controls micturition via cholinergic muscarinic receptors. The pudendal nerve exits the sacral spinal cord, and provides somatic innervation to the striated muscles of the external urethral sphincter.

In addition to their efferent function, each of these nerves carries afferent input from the LUT via the dorsal root ganglion (DRG). Information about bladder distention is carried by mechanosensitive afferents (A $\delta, C$ fibers) found primarily in the pelvic nerve. These afferents signal the coordinated switch between storage and micturition. The pudendal and hypogastric nerves mostly contain nociceptive afferents, which are not depicted here. (Modified from Inskip et al. 2009 Spinal Cord with permission ${ }^{5}$

sympathetic innervation from $\mathrm{T} 1-\mathrm{T} 5$ spinal sympathetic neurons, whereas the glands of the lower part of the body are under the control of the T5-L2 spinal sympathetic neurons (Table 1).

\section{Neural control of the lower urinary tract}

Lower urinary tract (LUT) function is controlled by neural circuits in the brain and spinal cord that coordinate the activity of visceral smooth muscle in the urinary bladder and urethra with activity of striated muscle in the external urethral sphincter. ${ }^{8}$ LUT function involves central pathways (supraspinal and spinal) and peripheral pathways (pelvic parasympathetic, lumbar sympathetic and somatic pudendal nerve). Axons of Onuf's nucleus in the sacral cord segments innervate the external urethral sphincter through the pudendal nerve. The bladder receives sympathetic innervation through hypogastric nerves and sacral parasympathetic innervation through pelvic nerves. Afferent information from the LUT enters the spinal segments and synapses on interneurons that either make local segmental connections with motor pathways or send their axons to the brain. Ascending pathways connect with structures in the brainstem, including the pons and periaqueductal gray matter of the midbrain to execute reflex functions. In conjunction, with higher centers of the brain (cingulate and frontal gyri), these reflexes mediate storage and conscious perception of sensations arising from the LUT. ${ }^{9}$ Activation of 


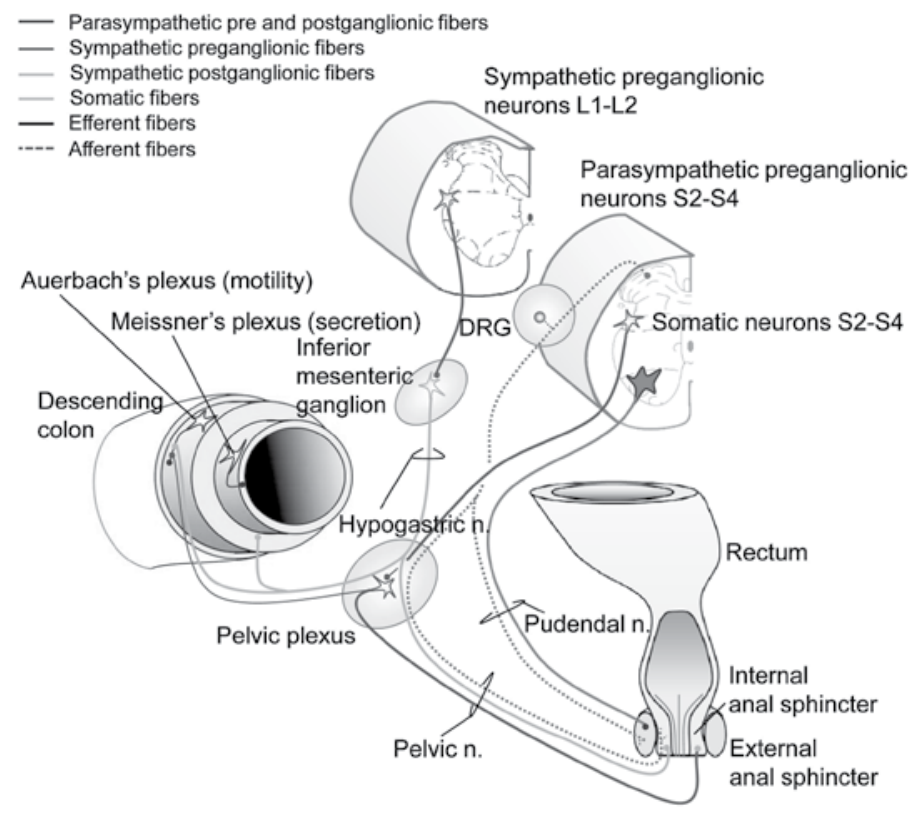

Figure 4. Innervation of the distal gastrointestinal tract. The enteric nervous system (ENS) is composed of two main ganglionated plexuses which lie between the longitudinal and circular muscle layers (myenteric or Auerbach's plexus) and within the submucosal layer (submucosal or Meissner's plexus) of the gastrointestinal (GI) tract. The myenteric plexus is continuous throughout the entire length of the Gl tract, and is primarily involved in the coordination of smooth muscle activity, while the submucosal plexus primarily controls secretion and absorption.

Autonomic innervation of the $\mathrm{Gl}$ tract is required to modulate the intrinsic activity of the ENS. In the distal GI tract (illustrated here), the ANS coordinates storage and evacuation by regulating colon motility and anal sphincter tone. Parasympathetic innervation of the distal colon and rectum originates in the sacral cord (S2-S4), while the upper GI tract (to the level of the splenic flexure) is innervated by the vagus nerve (not illustrated). Postganglionic parasympathetic neurons enhance smooth muscle activity (via acetylcholine). Sympathetic innervation is mainly postganglionic and inhibits muscle and secretory activity indirectly, by noradrenergic modulation of activity in both the Meissner and Auerbach's plexuses.

The internal anal sphincter receives both sympathetic and parasympathetic innervation, while the external anal sphincter is innervated by somatic fibers traveling in the pudendal nerve (S2-S4). Afferent information from this area travels in both the pelvic and pudendal nerves via dorsal root ganglion (DRG). (Modified from Inskip et al. 2009 Spinal Cord with permission ${ }^{5}$ )

the sympathetic circuits through spinal reflexes mediates detrusor muscle relaxation and bladder neck contraction, resulting in storage of urine. Activation of the sacral parasympathetic efferent neurons results in detrusor contraction which promotes voiding.

Normal volitional voiding is achieved with voluntary relaxation of the external urethral sphincter. The LUT micturition reflex pathway has two modes of operation: storage and elimination. In infants these mechanisms function in a reflex manner to produce involuntary voiding; however, in adults urine storage and elimination are subject to voluntary control as a result of connections between the forebrain and brainstem. SCI damages the spinal tracts involved in central control of the
LUT, often leading to simultaneous activation of parasympathetic neurons innervating the detrusor and somatic neurons innervating the external urethral sphincter. This conflicting abnormality causes varying degrees of loss of synergy or detrusor-sphincter dyssynergia.

\section{Neural control of the bowel}

Bowel function requires coordinated activity among the somatic, autonomic, and enteric nervous systems. Colonic peristalsis is coordinated by a network of neurons linking the brain to the colonic mucosa. The vagus nerve ( $\mathrm{CN} \mathrm{X})$ courses from the brainstem and innervates the gut down to the splenic flexure of the colon. The inferior 


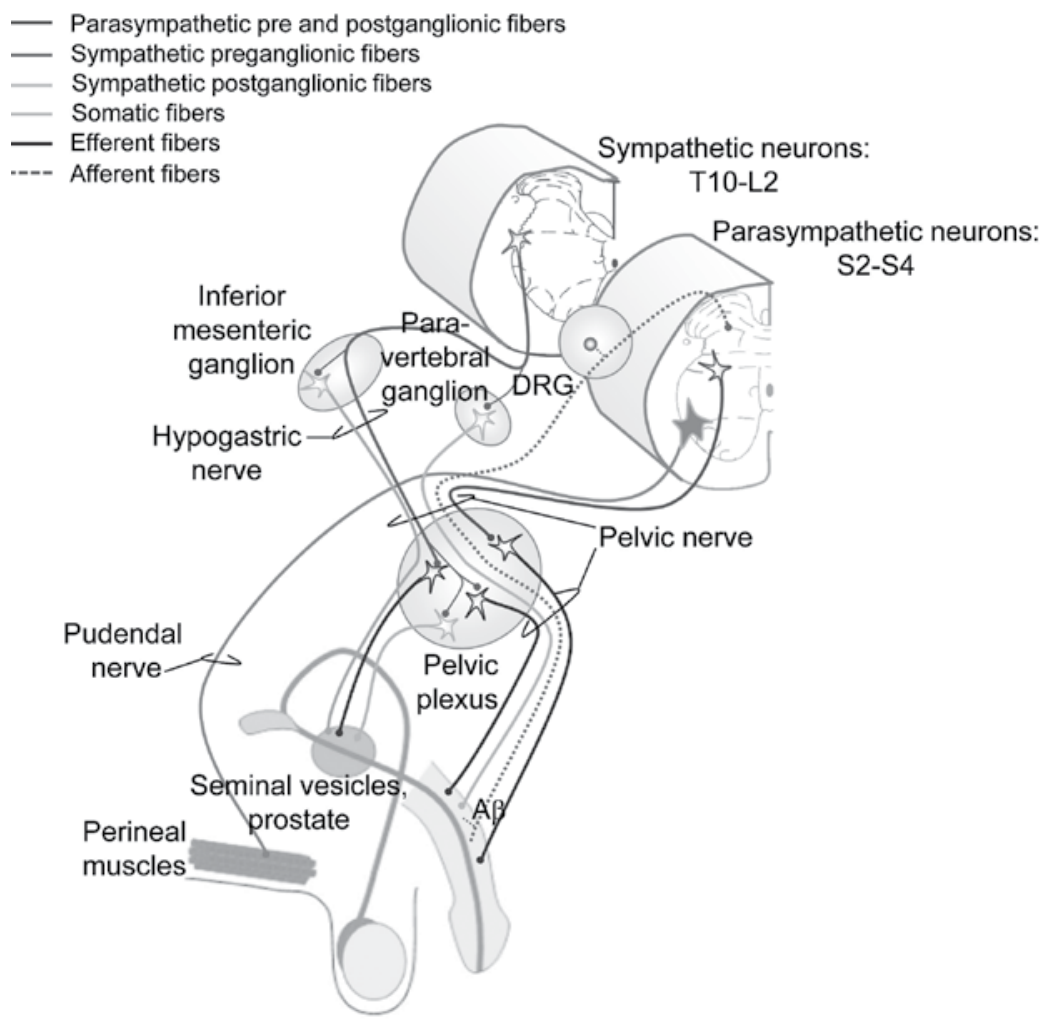

Figure 5. Innervation of the pelvic organs and male genitalia. In the pelvic organs and genitalia there are three main tissue types: secretory, erectile and striated muscle. The majority of the autonomic innervation to these tissues comes from the bilateral pelvic ganglia, which contains both sympathetic and parasympathetic neurons. Parasympathetic preganglionic neurons originate in the sacral cord (S2-S4) and travel in the pelvic nerve to the pelvic ganglia. Sympathetic innervation originates in the lower thoracic and lumbar cord (T10-L2) and travels via the hypogastic nerves to innervate the pelvic ganglia, sympathetic nerves also travel to the pelvic plexus via the pelvic nerve, which is mixed sympathetic and parasympathetic. These plexuses form a diffuse neural network on either side of the prostate (males) or cervix (females). In both sexes, the largest nerve exiting from the pelvic plexus is the cavernous nerve (also called penile nerve in males). For simplicity only innervation of the seminal vesicles is illustrated here. Somatic innervation of the striated perineal muscles, which include the ischiocavernosus, bulbocavernosus, and levator ani, originates in the sacral cord (S2-4). Afferent information from the pelvic organs is relayed to the spinal cord via the 'genito-spinal' nerves (pelvic, hypogastric and pudendal; for simplification, only the pelvic nerve is illustrated here) and sensory pathways ascend bilaterally in the dorsal quadrant of the spinal cord.

splanchnic nerve carries pelvic parasympathetic fibers from S2-4 of the spinal cord to the distal bowel (splenic flexure, the left colon and rectum). The enteric nervous system consists of two neuronal networks; the Auerbach's intramuscular myenteric plexus and Meissner's submucosal plexus. The myenteric plexus with unmyelinated fibers and postganglionic parasympathetic cell bodies mainly coordinates motility, while the submucosal plexus relays sensory and local motor responses. The internal anal sphincter is a continuation of the circular muscle layer of the rectum under reflex control by the enteric nervous system and S2-4 spinal segments of the spinal cord. The external anal sphincter and pelvic floor are supplied by the mixed motor and sensory somatic pudendal nerve providing voluntary control. There is also evidence of sympathetic control of the external anal sphincter. The bowel functions of storage, stool propulsion and defecation are dependent on coordinated control from the two components of the ANS, the enteric nervous system and voluntary motor 
control of the skeletal muscles of the pelvic floor and external anal sphincter. ${ }^{10}$

\section{Neural control of sexual responses}

Male and female sexual organs receive innervation from both components of the ANS. Similar to the LUT, sympathetic innervation is provided through the hypogastric nerve and parasympathetic innervation through the pelvic nerve. Psychogenic erection and vaginal lubrication are thought to be regulated by the sympathetic nervous system in conjunction with the parasympathetic. In contrast, reflex erection and vaginal lubrication are thought to be activated by the parasympathetic nervous system alone. ${ }^{11}$ Ejaculation is a neurologically more complicated phenomenon and relies on the coordination of the sympathetic (T11-L2) and parasympathetic (S2-4) nervous systems in addition to the somatic nervous system through the pudendal nerve (S25). Ejaculation and orgasm do not always coincide and neurologic control of orgasm is less well understood. However, studies in SCI suggest that an intact sacral reflex arc is necessary for orgasm to occur. ${ }^{11}$

\section{The Autonomic Standards Assessment Form}

\section{Anatomical classification}

An anatomical classification to describe the impact of SCI on urinary bladder, bowel and sexual function is recommended. Descriptive terms include supraconal, conal and cauda equina. Supraconal refers to those injuries occurring above the conus medullaris. In general, supraconal injuries cause an overactive or upper motor neuron pattern of damage affecting LUT, distal bowel and sexual functions. Conal injuries include those affecting the conus medullaris of the spinal cord and often cause a mixed lesion to LUT, distal bowel and sexual functions with a resultant either overactive or acontractile picture. Cauda equina injuries include those affecting the cauda equina and generally cause an acontractile or lower motor neuron picture affecting LUT, distal bowel and sexual function. It should be noted that the anatomical classification for autonomic function is intended to be used in conjunction with the ISNCSCI. Thus, in addition to using the above terminology, the examiner should provide information on the completeness of injury as determined by the preservation of perianal and deep anal pressure and voluntary anal contraction as described in the ISNCSCI, and the type of reflex activity present, as described in the autonomic standards.

\section{Classification of general autonomic function}

It is recommended that a detailed description of remaining general autonomic function be provided as part of the neurologic assessment of individual patients. This information should be documented through checks in the appropriate boxes in the table entitled General Autonomic Function (see Appendix I). The information is determined based on a combination of neurologic examination and clinical history.

The recognition and assessment of cardiac dysrhythmias includes documentation of bradycardia or HR under 60 beats per minute (bpm) and tachycardia or HR over $100 \mathrm{bpm}$. Other dysrhythmias should also be documented.

Abnormalities of arterial blood pressure (BP) include supine hypertension (BP greater than $140 / 90 \mathrm{mmHg}$ ) and supine hypotension (systolic BP less than $90 \mathrm{mmHg}$ ).

Orthostatic hypotension is a symptomatic or asymptomatic decrease in BP defined as a drop of at least $20 \mathrm{mmHg}$ systolic or $10 \mathrm{mmHg}$ diastolic within 3 minutes of moving from the supine to an upright position. ${ }^{12}$ Delayed decline in BP may also occur. Symptoms may include dizziness, headache or neck ache and fatigue.

Neurogenic shock is a commonly occurring condition during the acute period following SCI, associated with failure of the sympathetic nervous system resulting in loss of vascular tone in part of the body deprived from supraspinal control. In this condition, systolic BP $<90 \mathrm{mmHg}$ in the supine posture is not the result of low intravascular 
volume (e.g. blood loss, dehydration, sepsis, cardiac disorders) following SCI. While neurogenic shock is characterized by changes in BP and HR (autonomic), spinal shock is characterized by marked reductions in spinal reflex activity below the level of injury.

Autonomic dysreflexia is a constellation of signs and/or symptoms in SCI at and usually above T6 in response to noxious or non-noxious stimuli below the level of injury defined by an increase in systolic BP (>than $20 \mathrm{mmHg}$ above baseline), including headache, flushing, piloerection, stuffy nose, sweating above the level of the lesion, vasoconstriction below the level of the lesion and dysrhythmias. This syndrome may or may not be symptomatic and may occur at any period following SCI.

The autonomic components related to bronchopulmonary control are not easily tested at the bedside; however, it is important to document the respiratory capacity of individuals with SCI. Therefore, the need for complete or partial ventilatory assistance should be documented under broncho-pulmonary control.

Temperature dysregulation is defined as a change in body temperature (usually refers to core temperature) without signs of illness or infection and may result from exposure to environmental temperature change and should be documented.

Abnormalities of sudomotor function including hyperhydrosis or nonphysiological sweating in response to noxious/non-noxious stimuli; and hypohydrosis, diminished sweating below the level of the injury in response to a rise in temperature should be documented.

\section{Assessment of urinary bladder, bowel and sexual function}

Information related to urinary, bowel and sexual function is recorded in the table entitled Lower Urinary Tract, Bowel and Sexual Function and is based on the clinical examination and history (see Appendix I). The committee recognizes that other than urodynamics, no direct tests of autonomic integrity of LUT, distal bowel, and sexual function are generally available. Therefore, surrogate (sensory and motor) evaluation of autonomic control of these organ systems is recommended.

Consistent with the ISNCSCI sensory scoring system, possible responses are graded.

Patient self-reported responses include normal (2) when there is no change in neurologic control with respect to a specific function; reduced or altered (1) neurologic control with regard to a specific function; absent (0) neurologic control with regard to a specific function; and unable to assess a specific function (not testable, NT).

For the LUT, it is strongly recommended that urodynamics be routinely performed following SCI. The committee recognizes that some persons with SCI will not yet have had urodynamics. Clinicians would benefit from being able to communicate information regarding the patient's ability to perceive sensations related to bladder filling and voluntary control of voiding. It is therefore recommended that the following assessment be used until a urodynamic evaluation can be performed (see Appendix I). Furthermore, the clinician should consult the International SCI Data Sets for more information on recommended documentation of urologic assessments and procedures. Acknowledging the limitations of patient self-report, it is recommended that awareness of the need to empty the bladder (sensation) is first documented. Next, the ability to prevent leakage (continence) should be documented. The bladder emptying method should be recorded.

Due to a paucity of direct autonomic measurements, surrogate (sensory and motor) evaluation of autonomic control of the distal bowel includes: sensation of the need for a bowel movement, continence of stool, and the presence of voluntary sphincter contraction during anorectal examination.

Surrogate evaluation of autonomic control of sexual function includes: the presence of psychogenic genital arousal (penile erection or vaginal lubrication); reflex genital arousal; and ability to achieve orgasm. The presence of antegrade ejaculation is documented for males. The ability to sense menses (cramping, pain, etc.) relative to before injury is documented for females. 


\section{Recommendations for Recording Autonomic Function}

Both the ISNCSCI and the ISAFSCI can be performed at any time following SCI. Whereas the ISNCSCI is based purely on physical evaluation, the ISAFSCI takes into account self-reported history as well. A typical use might be acutely after injury, at discharge from the initial rehabilitation or during an annual physical evaluation. Both assessments can be used clinically for developing clinical treatment plans, research assessment, and therapeutic efficacy. There are no validation studies yet conducted related to the use of the ISAFSCI.

This edition of the Autonomic Standards Assessment Form (2012) has two components and each section has a different scoring method. A new and dated Assessment Form should be used when a section is scored or rescored. Subsequent autonomic assessments should include only data/ observations/patient reports after the previous assessment.

In addition to the ISAFSCI, the reader should be aware of the various International SCI Data Sets available to assist in the evaluation of autonomic function in individuals with spinal cord injury (see Appendix II $).{ }^{13}$

\section{Changes in the Autonomic Standards Assessment Form 2012}

This version of the Autonomic Standards Assessment Form (2012) underwent some modifications and revisions.

First, the committee made a decision to eliminate the previously included Urodynamics evaluation component of the form, as a majority of individuals will not have this assessment in the acute and sub-acute period of rehabilitation. Therefore, most of the time this component of the form will be left empty. However, the Autonomic Standards Committee encourages clinicians to consult the International Urodynamics SCI Data Set (4).

Second, we added an additionalline in the General Autonomic Functions Table entitled "Unable to assess" in the section entitled "Autonomic and Somatic Control of Bronchopulmonary System". This correction will make this part of the table consistent with other sections. This was omitted in our first edition.

Finally, ASIA and ISCoS logos are included as an indication of the collaborative work of two organizations on this project. 


\section{ASINA AppendixI ISCOS}

\section{Autonomic Standards Assessment Form}

Patient Name:

\section{General Autonomic Function}

\begin{tabular}{|c|c|c|c|}
\hline System/Organ & Findings & Abnormal conditions & $\begin{array}{l}\text { Check } \\
\text { mark }\end{array}$ \\
\hline \multirow{6}{*}{$\begin{array}{l}\text { Autonomic } \\
\text { control of the } \\
\text { heart }\end{array}$} & Normal & & \\
\hline & \multirow[t]{3}{*}{ Abnormal } & \begin{tabular}{|l} 
Bradycardia \\
\end{tabular} & \\
\hline & & \begin{tabular}{|l} 
Tachycardia \\
\end{tabular} & \\
\hline & & 0ther dysrhythmias & \\
\hline & Unknown & & \\
\hline & $\begin{array}{l}\text { Unable to } \\
\text { assess }\end{array}$ & & \\
\hline \multirow{6}{*}{$\begin{array}{l}\text { Autonomic } \\
\text { control of } \\
\text { blood } \\
\text { pressure }\end{array}$} & Normal & & \\
\hline & \multirow[t]{3}{*}{ Abnormal } & $\begin{array}{l}\text { Resting systolic blood pressure } \\
\text { below } 90 \mathrm{mmHg} \\
\end{array}$ & \\
\hline & & Orthostatic hypotension & \\
\hline & & Autonomic dysreflexia & \\
\hline & Unknown & & \\
\hline & $\begin{array}{l}\text { Unable to } \\
\text { assess }\end{array}$ & & \\
\hline \multirow{6}{*}{$\begin{array}{l}\text { Autonomic } \\
\text { control of } \\
\text { sweating }\end{array}$} & Normal & & \\
\hline & \multirow[t]{3}{*}{ Abnormal } & Hyperhydrosis above lesion & \\
\hline & & \begin{tabular}{|l|l} 
Hyperhydrosis below lesion \\
\end{tabular} & \\
\hline & & \begin{tabular}{|l|} 
Hypohydrosis below lesion \\
\end{tabular} & \\
\hline & Unknown & & \\
\hline & $\begin{array}{l}\text { Unable to } \\
\text { assess }\end{array}$ & & \\
\hline \multirow{5}{*}{$\begin{array}{l}\text { Temperature } \\
\text { regulations }\end{array}$} & Normal & & \\
\hline & \multirow[t]{2}{*}{ Abnormal } & Hyperthermia & \\
\hline & & \begin{tabular}{|l} 
Hypothermia \\
\end{tabular} & \\
\hline & Unknown & & \\
\hline & $\begin{array}{l}\text { Unable to } \\
\text { assess }\end{array}$ & & \\
\hline \multirow{6}{*}{$\begin{array}{l}\text { Autonomic and } \\
\text { Somatic Control } \\
\text { of Broncho- } \\
\text { pulmonary } \\
\text { System }\end{array}$} & Normal & & \\
\hline & \multirow[t]{3}{*}{ Abnormal } & $\begin{array}{l}\text { Unable to voluntarily breathe } \\
\text { requiring full ventilatory support }\end{array}$ & \\
\hline & & $\begin{array}{l}\text { Impaired voluntary breathing } \\
\text { requiring partial vent support }\end{array}$ & \\
\hline & & $\begin{array}{l}\text { Voluntary respiration impaired } \\
\text { does not require vent support }\end{array}$ & \\
\hline & Unknown & & \\
\hline & $\begin{array}{l}\text { Unable to } \\
\text { assess }\end{array}$ & & \\
\hline
\end{tabular}

Autonomic Diagnosis: (Supraconal $\square$, Conal $\square$, Cauda Equina $\square$ )

\section{Lower Urinary Tract, Bowel and Sexual Function}

\begin{tabular}{|c|c|c|}
\hline System/0rgan & & Score \\
\hline \multicolumn{3}{|l|}{ Lower Urinary Tract } \\
\hline \multicolumn{3}{|l|}{ Awareness of the need to empty the bladder } \\
\hline \multicolumn{3}{|l|}{ Ability to prevent leakage (continence) } \\
\hline \multicolumn{3}{|l|}{ Bladder emptying method (specify)__ } \\
\hline \multicolumn{3}{|l|}{ Bowel } \\
\hline \multicolumn{3}{|l|}{ Sensation of need for a bowel movement } \\
\hline \multicolumn{3}{|l|}{ Ability to Prevent Stool Leakage (continence) } \\
\hline \multicolumn{3}{|l|}{ Voluntary sphincter contraction } \\
\hline \multicolumn{3}{|l|}{ Sexual Function } \\
\hline \multirow[t]{2}{*}{ Genital arousal (erection or lubrication) } & Psychogenic & \\
\hline & Reflex & \\
\hline \multicolumn{3}{|l|}{ Orgasm } \\
\hline \multicolumn{3}{|l|}{ Ejaculation (male only) } \\
\hline Sensation of Menses (female only) & & \\
\hline
\end{tabular}

$2=$ Normal function, $1=$ Reduced or Altered Neurological Function $0=$ Complete loss of control, $N T=$ Unable to assess due to preexisting or concomitant problems

Date of Injury Date of Assessment

This form may be freely copied and reproduced but not modified. This assessment should use the terminology found in the International SCI Data Sets (ASIA and ISCOS - http://www.iscos.org.uk)

Examiner 


\section{Appendix II}

INTERNATIONAL SPINAL CORD INJURY

DATA SETS 4

Urodynamic Basic Data Set Form

Date performed: $\square$ Unknown

\section{Bladder sensation during filling cystometry:}

$\square$ Normal $\square$ Increased $\square$ Reduced $\square$ Absent

$\square$ Non-specific $\square$ Unknown

\section{Detrusor function}

$\square$ Normal $\square$ Neurogenic detrusor overactivity

$\square$ Underactive detrusor $\quad \square$ Acontractile detrusor

$\square$ Unknown

\section{Compliance during filling cystometry:}

Low $\left(<10 \mathrm{~mL} / \mathrm{cm} \mathrm{H}_{2} \mathrm{O}\right) \quad \square$ Yes $\square$ No $\square$ Unknown

Urethral function during voiding:

$\square$ Normal $\square$ Detrusor sphincter dyssynergia

$\square$ Non-relaxing urethral sphincter obstruction

$\square$ Not applicable $\square$ Unknown

Detrusor leak point pressure $\mathrm{Cm} \mathrm{H}_{2} \mathrm{O}$

$\square$ Not applicable $\square$ Unknown

Maximum detrusor pressure $\mathrm{Cm} \mathrm{H} \mathrm{H}_{2} \mathrm{O}$

$\square$ Not applicable $\square$ Unknown

Cystometric bladder capacity $\mathrm{mL}$

$\square$ Not applicable $\square$ Unknown

Post void residual volume $\mathrm{mL}$

$\square$ Not applicable $\square$ Unknown 


\section{Acknowledgments}

Permission has been given by Lawrence Vogel, MD, President of the American Spinal Injury Association, for publication of the 2012 Edition. Copies of the booklet can be obtained by contacting the ASIA office at: American Spinal Injury Association, Shepherd Center, 2020 Peachtree Road NW, Atlanta, GA 30309; phone: 404-355-9772; fax: 404-355-1926; e-mail: asia_ office@shepherd.org

\section{BIBLIOGRAPHY}

1. www.ASIAlearningcenter.com

2. American Spinal Injury Association: International Standards for Neurological Classification of Spinal Cord Injury, revised 2011 ; Atlanta, GA.

3. Alexander MS, Biering-Sorensen F, Bodner D, Brackett NL, Cardenas D, Charlifue S, Creasey G, Dietz V, Ditunno J, Donovan W, Elliott SL, Estores I, Graves DE, Green B, Gousse A, Jackson AB, Kennelly M, Karlsson AK, Krassioukov A, Krogh K, Linsenmeyer T, Marino R, Mathias CJ, Perkash I, Sheel AW, Shilero G, Schurch B, Sonksen J, Stiens S, Wecht J, Wuermser LA, Wyndaele JJ. International standards to document remaining autonomic function after spinal cord injury. Spinal Cord. 2009 Jan; $47(1): 36-43$

4. International urodynamic basic spinal cord injury data set. Biering-Sørensen F, Craggs M, Kennelly M, Schick E, Wyndaele JJ. Spinal Cord. 2008 Jul;46(7):513-6. Epub 2008 Jan 29.

5. Inskip JA, Ramer LM, Ramer MS, Krassioukov AV. Autonomic assessment of animals with spinal cord injury: tools, techniques and translation. Spinal Cord. 2009 Jan;47(1):2-35.

6. Krassioukov A, Claydon VE. The clinical problems in cardiovascular control following spinal cord injury: an overview. Prog Brain Res 2006; 152:223-229.
7. Schilero GJ, Spungen AM, Bauman WA, Radulovic $M$, Lesser M. Pulmonary function and spinal cord injury. Respir Physiol Neurobiol. 2009 May 15;166(3):129-141.

8. Yoshimura N, De Groat WC. Neural control of the lower urinary tract. Int Urol 1997; 4:111-125.

9. Mehnert U, Boy S, Svensson J, Michels L, Reitz A, Candia V et al. Brain activation in response to bladder filling and simultaneous stimulation of the dorsal clitoral nerve-an fMRI study in healthy women. Neuroimage. 2008;41:682-689.

10. Krogh K, Christensen P. Neurogenic colorectal and pelvic floor dysfunction. Best Pract Res Clin Gastroenterol. 2009; 23(4):531-543. Review.

11. Sipski ML, Alexander CJ, Rosen RC. Sexual arousal and orgasm in women: effects of spinal cord injury. Ann Neurol. 2001 Jan; 49(1):35-44

12. Consensus statement on the definition of orthostatic hypotension, pure autonomic failure, and multiple system atrophy. The Consensus Committee of the American Autonomic Society and the American Academy of Neurology. Neurol. 1996;46:1470.

13. http://www.iscos.org.uk/page.php? content $=20$ 